Article

\title{
A Summer Mortality Outbreak of Lactococcosis by Lactococcus garvieae in a Raceway System Affecting Farmed Rainbow Trout (Oncorhynchus mykiss) and Brook Trout (Salvelinus fontinalis)
}

\author{
Paolo Pastorino ${ }^{1, *(\mathbb{C}}$, Ana Isabel Vela Alonso ${ }^{2}$, Silvia Colussi ${ }^{1}$, Giulia Cavazza ${ }^{1}$, \\ Vasco Menconi ${ }^{1}$, Davide Mugetti ${ }^{1}$, Marzia Righetti ${ }^{1}$, Raffaella Barbero ${ }^{3}$ (D) Gaetano Zuccaro ${ }^{1}$, \\ José Francisco Fernández-Garayzábal ${ }^{2}$, Alessandro Dondo ${ }^{1}$, Pier Luigi Acutis ${ }^{1}$ and \\ Marino Prearo ${ }^{1}$ \\ 1 Istituto Zooprofilattico Sperimentale del Piemonte, Liguria e Valle d'Aosta, via Bologna 148, 10154 Torino, \\ Italy; silvia.colussi@izsto.it (S.C.); g.cavazza90@hotmail.it (G.C.); vasco.menconi@izsto.it (V.M.); \\ davide.mugetti@izsto.it (D.M.); marzia.righetti@gmail.com (M.R.); gaetanobem@hotmail.it (G.Z.); \\ alessandro.dondo@izsto.it (A.D.); pierluigi.acutis@izsto.it (P.L.A.); marino.prearo@izsto.it (M.P.) \\ 2 Centro de Vigilancia Sanitaria Veterinaria (VISAVET), Universidad Complutense de Madrid, \\ Avenida Puerta de Hierro, 28040 Madrid, Spain; avela@ucm.es (A.I.V.A.); garayzab@ucm.es (J.F.F.-G.) \\ 3 Azienda Sanitaria Locale di Biella, via Don Sturzo 20, 13900 Biella, Italy; raffaella.barbero@aslbi.piemonte.it \\ * Correspondence: paolo.pastorino@izsto.it; Tel.: +39-011-268-6295
}

Received: 31 October 2019; Accepted: 27 November 2019; Published: 29 November 2019

check for updates

Simple Summary: Lactococcus garvieae is the etiological agent of lactococcosis, a bacterial disease affecting many species of fish and causing major economic losses in aquaculture. In this study we described, for the first time, the isolation of L. garvieae in brook trout farmed in northwestern Italy by performing a molecular and epidemiological characterization. Results confirmed water as vehicle of infection, favoring the transmission of the pathogen between rainbow trout farmed in the upstream compartments of a raceways system and the brook trout located in downstream tanks.

\begin{abstract}
Lactococcosis is a fish disease of major concern in Mediterranean countries caused by Lactococcus garvieae. The most susceptible species is the rainbow trout (Oncorhynchus mykiss), suffering acute disease associated with elevated mortalities compared to other fish species. References reported that other salmonids are also susceptible to the disease, but no mortality outbreak has been described to date. The aim of this study was to present a mortality outbreak that occurred in brook trout (Salvelinus fontinalis) farmed in northwestern Italy during the summer of 2018. Fish exhibited clinical signs, such as exophthalmos, diffused hemorrhages localized in the ocular zone, hemorrhagic enteritis, and enlarged spleen. L. garvieae was isolated in all fish. Molecular and epidemiological characterization of the isolates, through Pulsed Field Gel Electrophoresis (PFGE), confirmed the initial hypothesis of water as vehicle of infection favoring transmission between rainbow trout farmed in upstream compartments and brook trout located in downstream tanks. Moreover, several environmental conditions affected and promoted the outbreak, among them the high-water temperature, which probably induced a physiological stress in brook trout, being way above the optimal temperature for this species, increasing the susceptibility to infection.
\end{abstract}

Keywords: aquaculture; fish diseases; outbreak; brook trout; Lactococcus garvieae 


\section{Introduction}

Streptococcosis is a disease responsible for septicemic processes in several freshwater and marine fish [1]. From an etiological point of view, streptococcosis are strictly linked to water temperature and are considered seasonal diseases divided into two groups: warm water infections that affect fish at a water temperature above $15{ }^{\circ} \mathrm{C}$ and cold-water infections pathogenic only for fish at temperatures below $15^{\circ} \mathrm{C}$ [2]. During the last decade, thanks to the development of new techniques of diagnosis based on genotypic characteristics, numerous changes in the taxonomy of bacteria involved in streptococcosis have been made, with the description of five bacterial genera: Streptococcus, Enterococcus, Lactococcus, Vagococcus, and Carnobacterium [3-5]. Etiological agents of warm water streptococcosis are represented by four species: Lactococcus garvieae [6], Streptococcus iniae [7], Streptococcus agalactiae [8], and Streptococcus parauberis [9].

Lactococcosis is caused by L. garvieae, a Gram-positive coccus, isolated from various species of aquatic animals [10-12] and from mastitis in cows and buffalos [10,13]. This microorganism has also been isolated from several clinical cases in humans, suggesting that $L$. garvieae should be considered as potential zoonotic agent [14]. Lactococosis is a disease of major concern in several trout farms mostly located on the plain causing high economic losses that can exceed approximately $50-80 \%$ of the total production $[2,6,15]$. The disease was described for the first time in Japan in an intensive farm of rainbow trout (Oncorhynchus mykiss) [16]. In regards to Europe, the first isolation was reported in Spain in 1993 [17] and, one year later, the same pathogen was also detected in Italy in intensive rainbow trout farms located in North Italy [6,15]. From that point on, this pathogen rapidly spread throughout the southern part of the European continent [18] thanks to its high virulence, the lack of suitable control methods, and the movement of infected fish [19].

Published data confirm a global increase of outbreaks affecting rainbow trout in several countries all over the world, such as Australia, South Africa, Japan, Taiwan [5], and the USA [20]. Therefore, L. garvieae can be considered a cosmopolitan pathogen. Transmission of the disease occurs by horizontal mechanisms, mainly through water, fish injuries, and by the fecal-oral route [21]. L. garvieae is responsible of a hyperacute and hemorrhagic septicemia, although the evolution of the disease strictly depends on environmental conditions, such as water temperature and water microbiological quality [18].

The gross pathology consists in a rapid and general anorexia, melanosis, lethargy, loss of orientation, and erratic swimming. Typical external signs of affected fish are exophthalmos, the presence of hemorrhages in the periorbital and intraocular area at the base of fins, in the perianal region, and in the buccal region. It is also very common to observe fish with swollen abdomens and anal prolapses. Algöet and co-workers [22] reported that other salmonids such as Atlantic salmon (Salmo salar), brown trout (Salmo trutta), and brook trout (Salvelinus fontinalis) were also susceptible to the disease, but no mortality outbreaks have been described in brook trout to date.

Italy is the first producer of freshwater salmonids in the EU and more than $65 \%$ of the production is yielded in North Italy. Rainbow trout is the most important farmed fish species but, even if in a smaller scale, other salmonids such as brook trout are produced, being sold for human consumption in both fresh and smoked form.

The aim of this study was to describe the first isolation of L. garvieae in brook trout farmed in northwestern Italy and to perform a molecular and epidemiological characterization of the isolates.

\section{Material and Methods}

A septicemic outbreak with typical symptoms of lactococcosis occurred between July and August 2018 in a trout farm located in northwestern Italy. The raceway system contained rainbow trout (300 q; $300 \mathrm{~g}$ medium sized) in the upstream compartments, and brook trout (150 q; 250-300 g medium sized) in the downstream tanks. Ninety-five percent of both rainbow trout and brook trout exhibited clinical signs, with a mortality rate of 70\% (8-10 kg/day fish losses) and 75\% (8-10 kg/day fish losses), respectively. The water temperature was $18-19^{\circ} \mathrm{C}$, at the limit of fish tolerance. 
On 8 August 2018, 25 recently moribund brook trout (250-300 g weight) and 25 rainbow trout (300 g weight) were sent refrigerated within $3 \mathrm{~h}$ to the Fish Diseases Laboratory of the Instituto Zooprofilattico Sperimentale del Piemonte, Liguria e Valle d'Aosta for further microbiological analysis. Fish were necropsied, and samples of kidney and brain were aseptically removed and used for further microbiological analyses.

For microbiological analysis, clinical specimens were grown on Columbia blood agar plates (Liofilchem, Italy) and incubated at $22{ }^{\circ} \mathrm{C} \pm 2{ }^{\circ} \mathrm{C}$ for $72 \mathrm{~h}$. Bacterial isolates were initially identified by using commercial Rapid ID32 STREP strips (bioMérieux, France) after an incubation period of $24 \mathrm{~h}$ at $37^{\circ} \mathrm{C} \pm 2{ }^{\circ} \mathrm{C}$. Additional phenotypic identification was carried out by the VITEK MS system (bioMérieux, France) according to the manufacturer's instructions. Phenotypic identification of L. garvieae isolates was confirmed by a species-specific PCR [23].

L. garvieae isolates $(n=16)$ were molecularly characterized (10 isolates from rainbow trout and six isolates from brook trout) by Pulsed Field Gel Electrophoresis (PFGE) with the enzymes ApaI and SmaI (MBI Fermentas) as described by Vela and co-workers [24] with the following modifications: running time, $21 \mathrm{~h}$; temperature, $14{ }^{\circ} \mathrm{C}$; voltage gradient, $6 \mathrm{~V} / \mathrm{cm}$; and included angle, $120{ }^{\circ} \mathrm{C}$, with an initial pulse time of $0.1 \mathrm{~s}$ and a final pulse time of $25 \mathrm{~s}$. XbaI-digested DNA from Salmonella enterica serotype Braenderup H9812 was used for molecular weight size determination.

\section{Results and Discussion}

Both trout species showed typical signs of lactococcosis, with erratic swimming, anorexia, lethargic behavior, melanosis (only in rainbow trout), exophthalmos, and hemorrhages in the periorbital and intraocular cavity as the most significant clinical signs and pathological findings being observed. Clinical signs (Figure 1) included diffuse hemorrhagic areas on the surface of internal organs (especially in liver and swim bladder) as well as in the ocular zone (with cases of ruptured globe), buccal area, opercula, fins and perianal area, hemorrhagic enteritis, enlarged spleen, and anal prolapse.

Pure culture of gram-positive, catalase-negative cocci were isolated in Columbia blood agar from the kidney and brain samples of all rainbow trout and brook trout analyzed. The morphological characteristics of the colonies and microscopic examination by Gram staining were identical for all the clinical isolates grown from the kidney and brain samples. Only 16 isolates were further biochemically identified and genetically characterized. Bacterial isolates were accurately identified as L. garvieae with both the Rapid ID32 STREP (API code: 30323500030, ID 99.9\%) and VITEK MS systems (ID 99.9\%). Additionally, all isolates gave the expected $1100 \mathrm{bp}$ PCR amplification product, which is specific for L. garvieae [23] confirming the biochemical identification.

After Pulsed Field Gel Electrophoresis (PFGE) analysis, the 10 L. garvieae isolated from rainbow trout exhibited undistinguishable PFGE patterns with each of the enzymes (Figure 2A,B, lanes 7 to 12 and lanes 14 to 17), which suggests that they represent a single clone of L. garvieae responsible for the outbreak in this trout species. The PFGE pattern obtained with the ApaI enzyme was undistinguishable from those previously identified in Italy [24]. This result suggests the potential of $L$. garvieae for long term persistence in the aquatic environment and/or on asymptomatic infected fish, being responsible for different lactococcosis outbreaks overtime.

Clinical isolates of L. garvieae from brook trout exhibited three and two PFGE patterns using ApaI (Figure 2A, pulsotype 1, lane 2; pulsotype 2, lane 3; and pulsotype 3, lanes 4-6 and 13) and SmaI (Figure 2B, pulsotype 1, lanes 2, 4-6, and 13 and pulsotype 2, lane 3) enzymes, respectively. Four (lanes 4-6 and 13) out of the six L. garvieae brook trout isolates characterized by PFGE, with the ApaI enzyme, exhibited a pulsotype undistinguishable from that found in rainbow trout isolates (Figure 2A), while the other two isolates exhibited different, although closely related, PFGE patterns (Figure 2A, lanes 2 and 3). 


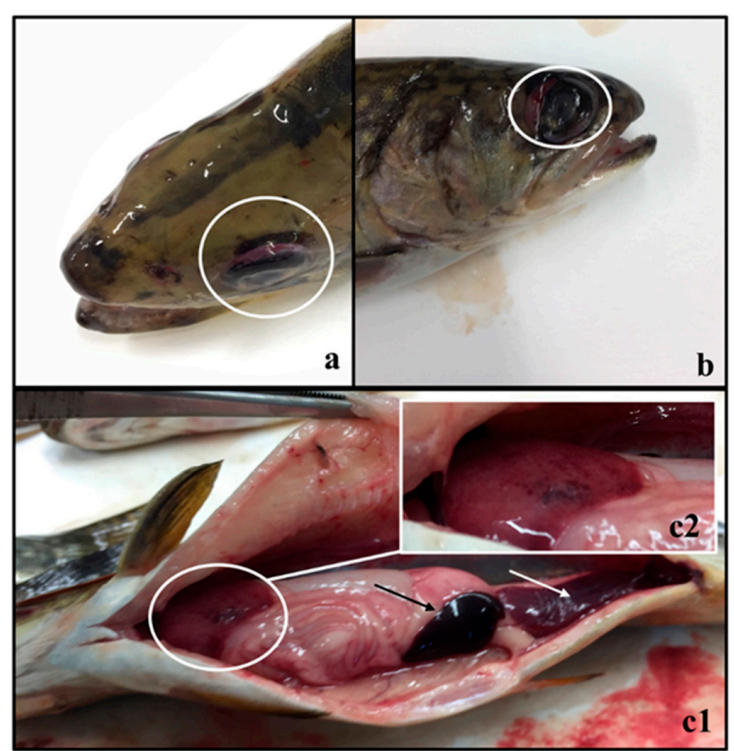

Figure 1. Clinical signs of lactococcosis observed in brook trout: (a) exophthalmos and haemorrhages in the periorbital and intraocular area; (b) ruptured globe; (c1) enlarged spleen (black arrow), hemorrhagic enteritis (white arrow), and (c2) diffused haemorrhages on liver.
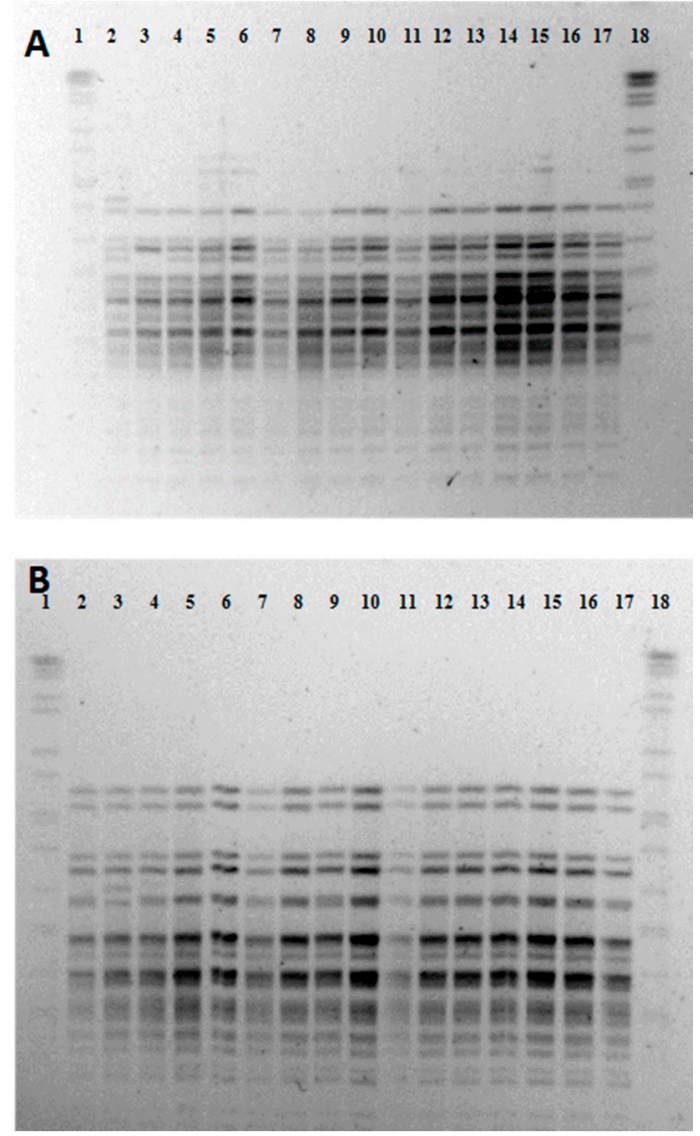

Figure 2. Pulsed-field gel electrophoresis patterns of $A p a I$ (A) and $S m a \mathrm{I}(\mathbf{B})$ digests of genomic DNA of Lactococcus garvieae clinical isolates. Lane 1 and 18, Salmonella serotype Branderup strain H9812; lanes 2-6 and lane 13, brook trout isolates from samples S-8, S-9, S-10, S-11 S-12, and S-7; lanes 7-12 and lanes 14-17, rainbow trout isolates of samples T-1, T-2, T-3, T-4, T-5, T-6, T-7, T-13, T-14, and T-15. 
This result indicates that different strains of L. garvieae can be found in a lactococcosis outbreak. L. garvieae is a genetically heterogeneous microorganism [25]. However, 14 out of the 16 isolates of L. garvieae of both trout species characterized by PFGE (87.5\%) exhibited the same pulsotype with the enzyme ApaI. This fact, together with their isolation in pure culture from internal organs of different animals over a period of two months, is indicative of its clinical significance. L. garvieae is able to infect many different fish species, such as yellowtail, tilapia, Japanese eel, olive flounder, grey mullet, catfish, wild wrasse, black rockfish, amberjack, kingfish, or giant fresh water prawn [7,26-32]. This is the first report of a lactococcosis outbreak affecting brook trout, which expand the range of fish species that can be affected by this pathogen.

There are several aquatic environmental factors such as fish stress, overcrowding, mishandling, poor water quality, and principally water temperature that influence the appearance of lactococcosis outbreaks [5]. Epidemiological data indicates that lactococcosis outbreaks usually occur during summer when water temperatures rise over $14-15^{\circ} \mathrm{C}[17,33]$. Therefore, the high-water temperature $\left(18-19^{\circ} \mathrm{C}\right)$ of the river was the most likely predisposing factor that contributed to the development of the outbreak in both rainbow and brook trout. Moreover, the temperature of the water was in the upper limit of the thermal tolerance for brook trout, which could induce cellular and endocrine stress responses [34] that might have increased susceptibility to L. garvieae infection in this fish species. No deficiencies in management practices were identified in either of both affected fish farms. Other factors related with the water quality, such as $\mathrm{pH}$, oxygen, or ammonium concentrations, were not recorded and are therefore impossible to be evaluated for their influence in the appearance and severity of the lactococcosis outbreak. Furthermore, no control measures (vaccination or therapeutic treatment) were used.

The application of chemotherapeutic agents is an unsustainable strategy in the control of lactococcosis due to the development of antibiotic resistance [12].

The application of preventatives in terms of biosecurity measures, such as destruction of moribund fish, regular and appropriate disinfection of equipment, improvement of health management measures, and immunization of healthy fish, are highly recommended in trout farms, particularly in those that use rivers as a source of water [35-38]. In fact, L. garvieae reach aquatic environments through contaminated feces of infected or diseased fish [39] being further transmitted through the fecal-oral route [21]. The tanks with brook trout were located downstream to those with rainbow trout. Therefore, it is likely that dissemination of L. garvieae from the rainbow trout to brook trout occurred through the contamination of the water.

Author Contributions: Data curation, P.P. and M.P.; investigation, P.P., A.I.V.A., S.C., G.C., V.M., D.M., M.R., R.B., G.Z., J.F.F.-G., and M.P.; methodology, P.P., A.I.V.A., S.C., G.C., V.M., D.M., M.R., J.F.F.-G., and P.L.A.; supervision, M.P.; writing—original draft, P.P.; writing—review \& editing, A.I.V.A., S.C., R.B., J.F.F.-G., A.D., P.L.A., and M.P.

Funding: This research received no external funding.

Acknowledgments: This study was supported by RTI2018-098530-B-I00 (Ministerio de Ciencia, Innovación y Universidades).

Conflicts of Interest: The authors declare no conflict of interest.

\section{References}

1. Osman, K.M.; Al-Maary, K.S.; Mubarak, A.S.; Dawoud, T.M.; Moussa, I.M.I.; Ibrahim, M.D.S.; Hessain, A.M.; Orabi, A.; Fawzy, N.M. Characterization and susceptibility of streptococci and enterococci isolated from Nile tilapia (Oreochromis niloticus) showing septicaemia in aquaculture and wild sites in Egypt. BMC Vet. Res. 2017, 13, 357. [CrossRef]

2. Eldar, A.; Ghittino, C. Lactococcus garvieae and Streptococcus iniae infection in rainbow trout (Oncorhynchus mykiss): Similar but different diseases. Dis. Aquat. Org. 1999, 36, 227-231. [CrossRef]

3. Wallbanks, S.; Martinez-Murcia, A.J.; Fryer, J.L.; Phillips, B.A.; Collins, M.D. 16s rRNA Sequence Determination for Carnobacterium and Related Lactic Acid of Vagococcus salmoninarum sp. nov. Members of the Genus Bacteria and Description. Int. J. Syst. Evol. 1990, 40, 224-230. [CrossRef] 
4. Michel, C.; Nougayrede, P.; Eldar, A.; Sochon, E.; de Kinkelin, P. Vagococcus salmoninarum, a bacterium of pathological significance in rainbow trout (Oncorhynchus mykiss) farming. Dis. Aquat. Organ. 1997, 30 , 189-208. [CrossRef]

5. Vendrell, D.; Balcázar, J.L.; Ruiz-Zarzuela, I.; de Blas, I.; Gironés, O.; Múzquiz, J.L. Lactococcus garvieae in fish: A review. Comp. Immunol. Microbiol. Infect. Dis. 2006, 29, 177-198. [CrossRef] [PubMed]

6. Ghittino, C.; Prearo, M. Report of Streptococcosis in rainbow trout (Oncorhynchus mykiss) in Italy: Preliminary note. Boll. Soc. Ital. Patol. Ittica 1992, 8, 4-11.

7. Colorni, A.; Ravelo, C.; Romalde, J.L.; Toranzo, A.E.; Diamant, A. Lactococcus garvieae in wild Red Sea wrasse Coris aygula (Labridae). Dis. Aquat. Org. 2003, 56, 275-278. [CrossRef]

8. $\quad$ Evans, J.J.; Klesius, P.H.; Gilbert, P.M.; Shoemaker, C.A.; Al Sarawi, M.A.; Landsberg, J.; Duremdez, R.; Al Marzouk, A.; Al Zenki, S. Characterization of $\beta$-Haemolytic Group B Streptococcus agalactiae in cultured seabream, Sparus auratus L., and wild mullet, Liza klunzingeri (Day), in Kuwait. J. Fish Dis. 2002, 25, 505-513. [CrossRef]

9. Doménech, A.; Fernández-Garayzábal, J.F.; Pascual, C.; Garcia, J.A.; Cutuli, M.T.; Moreno, M.A.; Collins, M.D.; Domínguez, L. Streptococcosis in cultured turbot, Scophthalmus maximus (L.), associated with Streptococcus parauberis. J. Fish Dis. 1996, 19, 33-38. [CrossRef]

10. Collins, M.D.; Farrow, J.A.; Phillips, B.A.; Kandler, O. Streptococcus garvieae sp. nov. and Streptococcus plantarum sp. nov.. J. Gen. Microbiol. 1983, 129, 3427-3431. [CrossRef]

11. Eldar, A.; Ghittino, C.; Asanta, L.; Bozzetta, E.; Goria, M.; Prearo, M.; Bercovier, H. Enterococcus seriolicida is a junior synonym of Lactococcus garvieae, a causative agent of septicemia and meningoencephalitis in fish. Curr. Microbiol. 1996, 32, 85-88. [CrossRef] [PubMed]

12. Meyburgh, C.M.; Bragg, R.R.; Boucher, C.E. Lactococcus garvieae: An emerging bacterial pathogen of fish. Dis. Aquat. Org. 2017, 123, 67-79. [CrossRef] [PubMed]

13. Teixeira, L.M.; Merquior, V.L.C.; Vianni, M.C.E.; Carvalho, M.G.S.; Fracalanzza, S.E.L.; Steigerwalt, A.G.; Brenner, D.J.; Facklam, R.R. Phenotypic and genotypic characterization of atypical Lactococcus garvieae strains isolated from water buffalos with subclinical mastitis and confirmation of L. garvieae as a senior subjective synonym of Enterococcus seriolicida. Int. J. Syst. Bacteriol. 1996, 46, 664-668. [CrossRef] [PubMed]

14. Chan, J.F.W.; Woo, P.C.Y.; Teng, J.L.L.; Lau, S.K.P.; Leung, S.S.M.; Tam, F.C.C.; Yuen, K.Y. Primary infective spondylodiscitis caused by Lactococcus garvieae and a review of human L. garvieae infections. Infection 2011, 39, 259-264. [CrossRef] [PubMed]

15. Ceschia, G.; Giorgetti, G.; Giavenni, R.; Sarti, M. A new problem for Italian trout farms: Streptococcosis in rainbow trout (Oncorhynchus mykiss). Bull. Eur. Assoc. Fish Pathol. 1992, 12, 2-72.

16. Hoshina, T.; Sano, T.; Morimoto, Y. A Streptococcus pathogenic to fish. J. Tokyo Univ. Fish. 1958, 44, 57-58.

17. Prieta,J.; Domènech, A.M.; Fernández-Garayzábal, J.F.; Collins, M.D.; Rodrígues, U.M.; Jones, D. Lactococcosis de la trucha arco iris (Oncorhynchus mykiss). Med. Vet. 1993, 10, 367-673.

18. Eyngor, M.; Zlotkin, A.; Ghittino, C.; Prearo, M.; Douet, D.G.; Chilmonczyk, S.; Eldar, A. Clonality and Diversity of the Fish Pathogen Lactococcus garvieae in Mediterranean Countries. Appl. Environ. Microbiol. 2004, 70, 5132-5137. [CrossRef]

19. Bercovier, H.C.; Ghittino, C.; Eldar, A. Immunization with bacterial antigens: Infections with streptococci and related organisms. Dev. Biol. Stand. 1997, 90, 153-160.

20. Perera, R.P.; Johnson, S.K.; Collins, M.D.; Lewis, D.H. Streptococcus iniae associated with mortality of Tilapia nilotica X T. aurea hybrids. J. Aquat. Anim. Health 1994, 6, 335-340. [CrossRef]

21. Afonso, A.; Silva, J.; Gomes, S. Lactococcus garvieae trout infections in Portugal: A new challenge on fish vaccinology. IBMC News 2003, 7, 4-6.

22. Algöet, M.; Bayley, A.E.; Roberts, E.G.; Feist, S.W.; Wheeler, R.W.; Verner-Jeffreys, D.W. Susceptibility of selected freshwater fish species to a UK Lactococcus garvieae isolate. J. Fish Dis. 2009, 32, 825-834. [CrossRef] [PubMed]

23. Zlotkin, A.; Eldar, A.; Ghittino, C.; Bercovier, H. Identification of Lactococcus garvieae by PCR. J. Clin. Microbiol. 1998, 36, 983-998. [PubMed]

24. Vela, A.I.; Vazquez, J.; Gibello, A.; Blanco, M.M.; Moreno, M.A.; Liebana, P.; Albendea, C.; Alcala, B.; Mendez, A.; Dominguez, L.; et al. Phenotypic and genetic characterization of Lactococcus garvieae isolated in Spain from lactococcosis outbreaks and comparison with isolates of other countries and sources. J. Clin. Microbiol. 2000, 38, 3791-3795. 
25. Tejedor, J.L.; Vela, A.I.; Gibello, A.; Casamayor, A.; Domínguez, L.; Fernández-Garayzábal, J.F. A genetic comparison of pig, cow and trout isolates of Lactococcus garvieae by PFGE analysis. Lett. Appl. Microbiol. 2011, 53, 614-619. [CrossRef]

26. Kusuda, K.; Kawai, K.; Salati, F.; Banner, C.R.; Fryer, J.L. Enterococcus seriolicida sp. nov., a fish pathogen. Int. J. Syst. Bacteriol. 1991, 41, 406-409. [CrossRef]

27. Lee, D.C.; Lee, J.I.; Park, C.I.; Park, S.I. The study on the causal agent of Streptococcosis (Lactococcus garvieae), isolated from cultured marine fishes. J. Fish Pathol. 2001, 14, 71-80.

28. Chen, S.C.; Lin, Y.D.; Liaw, L.L.; Wang, P.C. Lactococcus garvieae infection in the giant freshwater prawn Macrobranchium rosenbergii confirmed by polymerase chain reaction and $16 \mathrm{~S}$ rDNA sequencing. Dis. Aquat. Org. 2001, 45, 45-52. [CrossRef]

29. Chen, S.C.; Liaw, L.L.; Su, H.Y.; Ko, S.C.; Wu, C.Y.; Chang, H.C.; Tsai, Y.H.; Yang, K.L.; Chen, Y.C.; Chen, T.H.; et al. Lactococcus garvieae, a cause of disease in grey mullet, Mugil cephalus L., in Taiwan. J. Fish Dis. 2002, 25, 727-732. [CrossRef]

30. Ravelo, C.; Magarinos, B.; López-Romalde, S.; Toranzo, A.E.; Romalde, J.L. Molecular fingerprinting of fish-pathogenic Lactococcus garvieae strains by random amplified polymorphic DNA analysis. J. Clin. Microbiol. 2003, 41, 751-756. [CrossRef]

31. Kang, S.H.; Shin, G.W.; Shin, Y.S.; Palaksha, K.J.; Kim, Y.R.; Yang, H.H.; Lee, E.Y.; Lee, E.G.; Huh, N.E.; Ju, O.M.; et al. Experimental evaluation of pathogenicity of Lactococcus garvieae in black rockfish (Sebastes schlegeli). J. Vet. Sci. 2004, 5, 387-390. [CrossRef] [PubMed]

32. Kawanishi, M.; Kojima, A.; Ishihara, K.; Esaki, H.; Kijima, M.; Takahashi, T.; Suzuki, S.; Tamura, Y. Drug resistance and pulsed-field gel electrophoresis patterns of Lactococcus garvieae isolates from cultured Seriola (yellowtail, amberjack and kingfish) in Japan. Lett. Appl. Microbiol. 2005, 40, 322-328. [CrossRef]

33. Ghittino, C.; Muzquiz, J.L. La estreptococosis de la trucha arco iris en Espana. Resumen de lo expuesto en la reunion de piscicultores de Zaragoza del 26 de enero de 1998. Rev. Aquat. 1998, 2, 1-3.

34. McCormick, J.H.; Jones, B.R.; Hokanson, K.E.F. Effects of temperature on growth and survival of young brook trout, Salvelinus fontinalis. J. Fish. Res. Board Can. 1972, 29, 1107-1112. [CrossRef]

35. Prearo, M. Igiene zootecnica: Pratiche gestionali per un'acquacoltura sostenibile. Ittiopatologia 2007, 4, 19-39.

36. Soltani, M.; Nikbakht, G.; Ebrahimzadeh Moussavi,H.A.; Ahmadzadeh, N. Epizootic outbreak of lactococcosis caused by Lactococcus garvieae in farmed rainbow trout (Oncorhynchus mykiss) in Iran. Bull. Eur. Assoc. Fish. Pathol. 2008, 28, 95-106.

37. Prearo, M. La vaccinazione in acquacoltura. Ittiopatologia 2009, 6, 171-186.

38. Karsidani, S.H.; Soltani, M.; Nikbakhat-Brojeni, G.; Ghasemi, M.; Skall, H.F. Molecular epidemiology of zoonotic streptococcosis/lactococcosis in rainbow trout (Oncorhynchus mykiss) aquaculture in Iran. Iran. J. Microbiol. 2010, 2, 198-209.

39. Múzquiz, J.L.; Royo, F.M.; Ortega, C.; de Blas, I.; Ruiz, I.; Alonso, J.L. Pathogenicity of streptococcosis in rainbow trout (Oncorhynchus mykiss): Dependence on age and diseased fish. Bull. Eur. Assoc. Fish Pathol. $1999,19,114-119$.

(C) 2019 by the authors. Licensee MDPI, Basel, Switzerland. This article is an open access article distributed under the terms and conditions of the Creative Commons Attribution (CC BY) license (http://creativecommons.org/licenses/by/4.0/). 